\title{
Enhancing The Quality Of University Career Services In Taiwan: Perceptions Of University Alumni
}

Hsuan-Fu Ho, National Chiayi University, Taiwan

Wei-Ting Huang, The University of Edinburgh, United Kingdom

Tien-Ling Hu, National Chiayi University, Taiwan

\begin{abstract}
An adequate supply of a high quality labor force is crucial for national economic and social well-being; consequently, nations worldwide have placed significant emphasis on university graduate employability. Nonetheless, in Taiwan, a mismatch between knowledge acquired in universities and competences required by the job market has dramatically encumbered the supply of a high quality labor force. Thus, this research endeavored to determine the major career services that should be offered in higher educational institutions to alleviate the aforementioned human resource problems. The analytic hierarchy process was adopted as the major instrument for calculating the relative importance of each career service task, and 169 university alumni working in four major career fields participated in this research. The results indicated that participants from different career fields and who graduated from different colleges at different times have very different opinions of job service requests; therefore, universities should seriously consider the differences among students and provide the necessary services for each student in line with his/her particular requests. Moreover, although almost all participants agreed that sharpening students' job-search and interview skills was crucial in assisting students to find their first jobs, this service was extremely insufficient in universities, and universities thus have to place particular emphasis on this task in the future.
\end{abstract}

Keywords: Higher Education; Human Resource; Employability; Career Service

\section{INTRODUCTION}

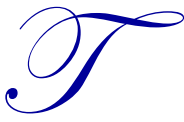

he emergence of the knowledge-based economy over the last two decades has driven the requests for high skilled laborers for economic development worldwide. Since higher educational institutions have been considered as the center of knowledge development in most countries, they are assigned the responsibility of providing an adequate labor force with advanced knowledge and skills to sustain a robust foundation for national economic and social development (Andrews \& Higson, 2008).

Adding to the mandates from governments and businesses, universities themselves also stress graduate employability. Under the recent trend of educational decentralization and privatization, most universities around the globe have shifted into a market-oriented pattern, and schools have to compete to attract sufficient customers (students) to survive the new educational market. As graduates' employability is one of the most important determinants for educational product evaluation, it has become crucial for universities to ensure a high graduate employment rate (Hirschi, 2012; Lucas, 1986; Wehrly, 1982; Yorke \& Knight, 2007).

Accordingly, most higher education institutions have established independent career service centers or employment management systems to better provide their students with the knowledge and skills requested by the labor market (Lucas, 1986). In addition, as people today tend to change careers repeatedly, career service centers are not focusing only on equipping students with the skills necessary to find a job right after graduation, but also endeavoring to assist students to have successful future career development, which is defined as self-directed management (SDCM) or a personal development plan (PDP) (Hirschi, 2012; Sun \& Yen, 2012). 
From employers' perspective, employment management refers to immediate work-readiness for job applicants, which includes the possession of the skills, knowledge, and attitudes important for accomplishing career tasks (Mason, Williams, \& Cranmer, 2009). From the perspective of universities and students, however, employment management should help ensure that graduates find the most adequate employment and students have sound performance, adaptation, and future development in workplaces (Hagner, Phillips, \& Dague, 2014; Herr, 1982; Jackson \& Wilton, 2016; McQuaid, Green, \& Danson, 2005).

Accordingly, the tasks of schools' career service centers should be designed to fulfill the contents listed in the aforementioned theories, which can further be categorized as follows: (1) helping students identify their aptitudes and interests; (2) providing students with a variety of career information and employment trends; (3) assisting students in learning and practicing career-related knowledge and skills ; (4) providing students with practical training for acquiring jobs, such as career searching, résumé writing, and interview skills; and (5) establishing relationships with companies to broaden students' employment opportunities (Sun \& Yen, 2012; Wu, Tsai, \& Chen, 2014).

Currently, most career services staff are those majoring in general physiology or psychological counseling; however, career services relying mainly on non-professionals or psychological counseling systems often cannot accomplish the missions of job services. Rather, a competent employment manager should possess professional knowledge in a variety of occupations and workplaces. Moreover, it is quite difficult to really enhance the graduate employment rate if a school relies merely on the career service center. Instead, working across departments is critical, and only when school members from different departments can collaborate as a team to better prepare their students can graduate employability be enhanced (Daniels, Stewart, Stupnisky, Perry, \& LoVerso, 2011; Hendricks, 1994; Osborne \& Usher, 1994).

Universities in Taiwan are currently facing significant difficulties in enhancing their graduate employability rate. According to Taiwan's government, despite the record high unemployment rate of $14.5 \%$ among 15 - to 24 -year-olds in 2009, around half of employers in Taiwan indicated that they had difficulties finding enough skilled workers. Facing the business needs as well as Taiwan government's mandates, universities in Taiwan have tried to revamp their curricula as well as their career service systems in line with the market requirements. Therefore, this research endeavors to explore what universities can do to better prepare their students for the job market in Taiwan. By analyzing the information provided by university alumni currently working in the job market, it seeks to address three research objectives:

1. Identifying the major tasks of university career services;

2. Calculating the relative importance of each task; and

3. Analyzing the variations in perceptions concerning task importance among different demographic groups.

\section{METHODOLOGY}

This research aims to identify the major career services universities should provide to students to meet the demands of the job market, calculate the relative importance of each task, and compare the perceived differences concerning task importance among different university graduate groups. The analytic hierarchy process (AHP) was adopted as the major method for accomplishing the aforementioned objectives.

Analytic hierarchy process (AHP) is a multi-criteria technique to solve complex comparative questions; it is quite powerful in decision making and policy development. The fundamental idea of AHP is to break a big problem into smaller elements and then create an AHP structure through a process of logical deductions. Thereafter, pairwise comparisons and positive reciprocals are implemented to generate the relative importance (weight) for each element. Although AHP allows a certain degree of inconsistency because human judges are not always consistent, a consistency index based on the eigenvalue of Lambda max is used to ensure that the inconsistency is limited within the acceptable levels. 
As shown in Figure 1, the Analytic hierarchy process (AHP structure for this research is composed of three levels. The first level is the main goal of this research: building a strong job service system at the higher educational level. The main goal is then divided into five measurement criteria, and each criterion is composed of two career service tasks.

Figure 1. The Analytic Hierarchy Process Structure for this Research

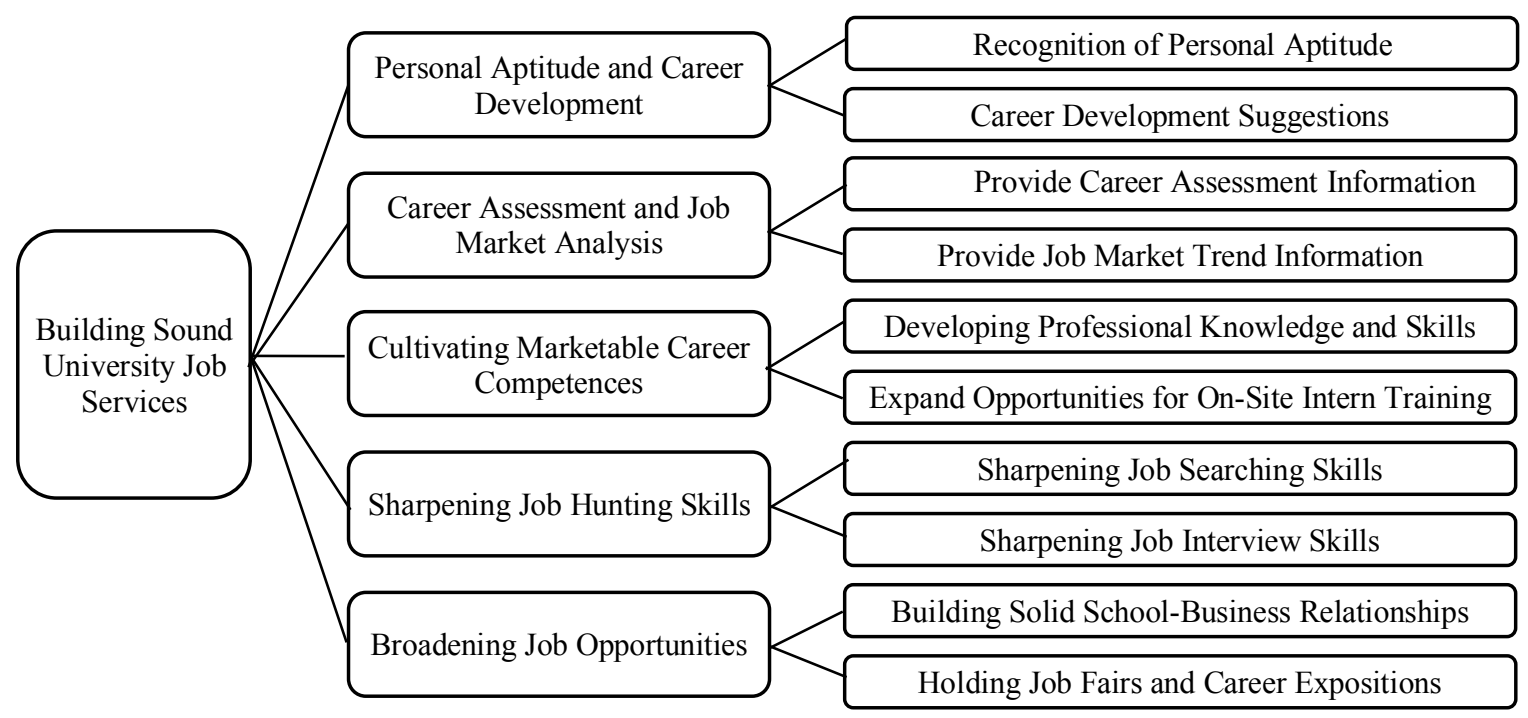

A self-developed questionnaire entitled "Survey of the Relative Importance and Implementation of University Job Services" was used as the major tool for data collection. A draft questionnaire was reviewed by five experts (scholars) to ensure that all questions were adequate, and a pilot test of the questionnaire was conducted with eight graduates from four different academic fields.

The research participants are full-time employees in different job fields, and all of them possess a higher education diploma. Given their career experiences in the real workplace for many years, we believe these people know best about how universities could revamp their job service system to better prepare their students for the job market. After making minor corrections to the questionnaire, the final version was administered to 400 university graduates; 169 questionnaires were returned, of which 150 were valid for analysis. Of the valid responses, $44.7 \%$ were from males, and $55.3 \%$ were from females. Moreover, $28.7 \%$ of the participants were from the field of social sciences, $20.0 \%$ were from business management, $24 \%$ were from engineering, and $27.3 \%$ were from agricultural sciences.

\section{RESEARCH RESULTS}

The research results indicated that, in general, expanding opportunities for on-site or intern training are the most important job service task universities should perform, followed by building solid school-business relationships, developing students' professional knowledge, sharpening job interview skills, and providing students with the latest career assessments. Meanwhile, holding job fairs and career expositions and assisting students in recognizing their personal attitudes are comparatively less important (see Table 1). 
Table 1. Rankings of Job Service Tasks

\begin{tabular}{l|cc}
\hline \multicolumn{1}{c}{ University Job Service } & Weight & Ranking \\
\hline Recognition of Personal Aptitude & 0.072 & 9 \\
\hline Career Development Suggestions & 0.076 & 5 \\
\hline Provide Latest Career Assessment & 0.094 & 6 \\
\hline Provide Job Market Trend Information & 0.085 & 3 \\
\hline Develop Professional Knowledge and Skills & 0.118 & 1 \\
\hline Expand Opportunities for On-Site Training & 0.168 & 8 \\
\hline Sharpen Résumé and Job Searching Skills & 0.073 & 4 \\
\hline Sharpen Job Interview Skills & 0.108 & 2 \\
\hline Build Solid School-Business Relationships & 0.136 & 10 \\
\hline Hold Job Fairs and Career Expositions & 0.071 & \\
\hline
\end{tabular}

We were interested in investigating the perception differences between male graduates and female graduates; the research results indicated that both male and female participants rated expanding opportunities for on-site intern training as the most important job service, followed by building solid school-business relationships, developing professional knowledge and skills, and sharpening job interview skills. However, male participants stressed assisting students' recognition of their personal aptitudes more than their female counterparts whereas female graduates emphasized providing the latest career assessments more than male graduates (see Table 2).

Table 2. Rankings of Job Service Tasks by Gender

\begin{tabular}{|c|c|c|c|c|}
\hline University Job Service & Male & Ranking & Female & Ranking \\
\hline Recognition of Personal Aptitude & 0.095 & 5 & 0.057 & 10 \\
\hline Career Development Suggestions & 0.076 & 9 & 0.074 & 7 \\
\hline Provide Latest Career Assessment & 0.083 & 7 & 0.102 & 5 \\
\hline Provide Job Market Trend Information & 0.093 & 6 & 0.077 & 6 \\
\hline Develop Professional Knowledge and Skills & 0.110 & 3 & 0.124 & 3 \\
\hline Expand Opportunities for On-Site Training & 0.150 & 1 & 0.183 & 1 \\
\hline Sharpen Résumé and Job Searching Skills & 0.074 & 10 & 0.071 & 8 \\
\hline Sharpen Job Interview Skills & 0.99 & 4 & 0.114 & 4 \\
\hline Build Solid School-Business Relationships & 0.140 & 2 & 0.132 & 2 \\
\hline Hold Job Fairs and Career Expositions & 0.079 & 8 & 0.065 & 9 \\
\hline
\end{tabular}

Participants from different career fields showed very different opinions toward the relative importance of the job service tasks. Participants working in social sciences, business management, and agriculture had very similar opinions, and they all indicated that expanding opportunities for on-site training was much more important than all the other tasks; meanwhile, they believed that assisting students in recognizing their personal aptitudes and providing students with career development suggestions were relatively less important. Engineering workers, however, revealed that helping students recognize their personal aptitudes was more important than all the other tasks, and they also significantly emphasized providing students with career development suggestions (see Table 3).

Table 3. Rankings of Job Service Tasks by Field of Career

\begin{tabular}{|c|c|c|c|c|}
\hline University Job Service & Social Sciences & Business & Engineering & Agriculture \\
\hline Recognition of Personal Aptitude & 0.06 & 0.05 & 0.12 & 0.06 \\
\hline Career Development Suggestions & 0.08 & 0.07 & 0.11 & 0.05 \\
\hline Provide Career Assessment Information & 0.09 & 0.11 & 0.11 & 0.07 \\
\hline Provide Job Market Trend Information & 0.08 & 0.08 & 0.11 & 0.07 \\
\hline Develop Professional Knowledge and Skills & 0.14 & 0.09 & 0.09 & 0.14 \\
\hline Expand Opportunities for On-Site Training & 0.18 & 0.18 & 0.08 & 0.26 \\
\hline Sharpen Résumé and Job Searching Skills & 0.08 & 0.05 & 0.09 & 0.07 \\
\hline Sharpen Job Interview Skills & 0.11 & 0.12 & 0.09 & 0.10 \\
\hline Build Solid School-Business Relationships & 0.13 & 0.15 & 0.11 & 0.13 \\
\hline Hold Job Fairs and Career Expositions & 0.06 & 0.09 & 0.10 & 0.04 \\
\hline
\end{tabular}


Research participants who graduated from comprehensive universities tended to assign higher weights to expanding opportunities of on-site trainings and building solid school-business relationships than those who graduated from polytechnic universities, whereas graduates from polytechnic universities highlighted honing job searching skills and interview skills more than their comprehensive university counterparts (see Table 4).

Table 4. Rankings of Job Service Tasks by Type of University

\begin{tabular}{l|c|c}
\hline \multicolumn{1}{c}{ University Job Service } & Comprehensive University & Polytechnic University \\
\hline Recognition of Personal Aptitude & 0.07 & 0.09 \\
\hline Career Development Suggestions & 0.07 & 0.09 \\
\hline Provide Career Assessment Information & 0.09 & 0.11 \\
\hline Provide Job Market Trend Information & 0.08 & 0.11 \\
\hline Develop Professional Knowledge and Skills & 0.12 & 0.11 \\
\hline Expand Opportunities for On-Site Training & 0.18 & 0.13 \\
\hline Sharpen Résumé and Job Searching Skills & 0.07 & 0.10 \\
\hline Sharpen Job Interview Skills & 0.11 & 0.09 \\
\hline Build Solid School-Business Relationships & 0.15 & 0.10 \\
\hline Hold Job Fairs and Career Expositions & 0.07 & 0.06 \\
\hline
\end{tabular}

Years after graduation is also an important variable for analyzing the trends and changes of the importance of job service tasks. Although all participants agreed that expanding the on-site learning opportunities and building solid school-business relationships were the most important tasks schools should accomplish, participants who graduated from school fewer than three years earlier tended to stress assisting students in recognizing their personal aptitude and providing students with career development suggestions whereas those who graduated four to six years earlier and seven to nine years earlier emphasized sharpening interview skills more than other participants (see Table 5).

Table 5. Rankings of Job Service Tasks by Years Since Graduation

\begin{tabular}{l|c|c|c|c}
\hline \multicolumn{1}{c}{ University Job Service } & 3 years or fewer & 4-6 years & 7-9 years & $\mathbf{1 0 +}$ years \\
\hline Recognition of Personal Aptitude & 0.12 & 0.07 & 0.04 & 0.04 \\
\hline Career Development Suggestions & 0.10 & 0.07 & 0.05 & 0.07 \\
\hline Provide Career Assessment Information & 0.09 & 0.10 & 0.09 & 0.08 \\
\hline Provide Job Market Trend Information & 0.09 & 0.07 & 0.11 & 0.08 \\
\hline Develop Professional Knowledge and Skills & 0.11 & 0.12 & 0.12 & 0.11 \\
\hline Expand Opportunities for On-Site Training & 0.14 & 0.16 & 0.20 & 0.21 \\
\hline Sharpen Résumé and Job Searching Skills & 0.07 & 0.09 & 0.06 & 0.07 \\
\hline Sharpen Job Interview Skills & 0.08 & 0.12 & 0.14 & 0.10 \\
\hline Build Solid School-Business Relationships & 0.13 & 0.12 & 0.14 & 0.16 \\
\hline Hold Job Fairs and Career Expositions & 0.07 & 0.08 & 0.05 & 0.08 \\
\hline
\end{tabular}

Thereafter, we examined the level of satisfaction with the implementation of each university job service. The results indicated that participants mostly recognized the universities' efforts in developing students' professional knowledge and skills, followed by expanding opportunities for on-site training and providing students with career assessment information. However, universities less commonly satisfy their graduates' requests for the service tasks of sharpening students' interview skills, sharpening job searching skills, providing students with personal career development suggestions, and assisting students in recognizing their aptitudes. 
Table 6. Participants' Satisfaction with Previous University Job Service Experiences

\begin{tabular}{l|c|c}
\hline University Job Service & Mean & SD \\
\hline Recognition of Personal Aptitude & 2.93 & .74 \\
\hline Career Development Suggestions & 2.90 & .77 \\
\hline Provide Career Assessment Information & 3.22 & .80 \\
\hline Provide Job Market Trend Information & 3.11 & .80 \\
\hline Develop Professional Knowledge and Skills & 3.53 & .89 \\
\hline Expand Opportunities for On-Site Training & 3.30 & 1.00 \\
\hline Sharpen Résumé and Job Searching Skills & 2.80 & .93 \\
\hline Sharpen Job Interview Skills & 2.66 & .93 \\
\hline Build Solid School-Business Relationships & 3.20 & .90 \\
\hline Hold Job Fairs and Career Expositions & 3.17 & .89 \\
\hline
\end{tabular}

\section{CONCLUSIONS AND IMPLICATIONS}

Business executives in Taiwan are now facing serious problems in finding a sufficient qualified labor force, while university graduates are facing difficulties in finding full-time jobs. Thus, this research endeavored to determine the major tasks of university job services, calculate the relative importance of each task, and investigate job service request differences among alumni currently working in various career fields. AHP was adopted as the major instrument for calculating the relative importance of each task, and alumni with full-time jobs from different career fields participated in this research.

The research findings indicated that participants considered expanding opportunities for on-site training as the most important service task that should be provided by universities, followed by building solid school-business relationships and assisting students in developing marketable professional knowledge and skills. However, when we examined the level of satisfaction with the service tasks, the average implementation score of sharpening students' job interview skills was comparatively lower given that it was fairly evenly emphasized by research participants. Therefore, we would suggest that universities put a particular emphasis on this task in the future.

The results also indicated that participants working in different career fields have very different job service requests: Participants working in the social science and agricultural fields stressed developing marketable professional knowledge much more than those from other career fields whereas participants working in the engineering field emphasized assisting students in recognizing their career aptitude more than participants from all the other fields. Moreover, the research results indicated that the different genders had very different job service requests. Although research participants indicated that students in different majors tend to have very different career requests, universities often ignore the differences among students and provide students from all academic fields with only one uniform set of services. As ignoring such differences among students can lead to inefficient or even erroneous job services, we would strongly suggest that universities seriously consider the differences among students and provide the necessary information for each student in line with his/her particular career service requests.

Another important finding is that employees who graduated at different times often have very different job service requests. This phenomenon can be attributed to the ever-changing nature of the job market. Therefore, it is important for universities to update their job market trend information often so that the most appropriate job services can be provided to their students. Another implication of this research result is that, facing the ever-changing job market, our study is only appropriate at one moment in time; thus, similar research should be conducted frequently in the future to ensure that the most updated and appropriate university job services can be accomplished.

Although our research identifies many job service truths and trends important to university job services, many results are lacking reasonable explanations. For example, why did participants in general stress expanding opportunities for on-site training and building solid school-business relationships more than all other service tasks? Furthermore, why did employees who graduated from different academic departments have very different job service requests? Recognizing the reasons leading to our research results is valuable for successfully improving the current university job service system. Therefore, we would highly recommend that an in-depth quantitative research 
be conducted in the future to explore and/or ascertain the origins of the current findings as well as enrich the knowledge base of university job services and the job market as a whole.

\section{AUTHOR BIOGRAPHIES}

Hsuan-Fu Ho is a professor teaching at National Chiayi University, Taiwan. His research area are educational finance, educational economics, and educational marketing. Email: hfho@mail.ncyu.edu.tw

Wei-Ting Huang gained her M.Sc. at the University of Edinburgh, UK. Her research area are comparative education and international education. Email: pooh04193324@gmail.com

Tien-Ling Hu gained her B.A. from National Chiayi University, Taiwan. Her research area are educational administration, and policy development. Email: Sarahtien00@gmail.com

\section{REFERENCES}

Andrews, J., \& Higson, H. (2008). Graduate employability, soft skills versus hard business knowledge: A European study. Higher Education in Europe, 33(4), 411-422.

Daniels, L. M., Stewart, T. L., Stupnisky, R. H., Perry, R. P., \& LoVerso, T. (2011). Relieving career anxiety and indecision: The role of undergraduate students' perceived control and faculty affiliations. Social Psychology of Education, 14(3), 409426.

Hagner, D., Phillips, K. J., \& Dague, B. (2014). Implementation of an employment consultation model of job support following online training. Journal of Rehabilitation, 80(4), 19-27.

Hendricks, F. M. (1994). Career counseling with African American college students. Journal of Career Development, 21(2), $117-126$.

Herr, E. L. (1982). A summary of the international consultation on career guidance in higher education. International Journal for the Advancement of Counseling, 5, 223-231.

Hirschi, A. (2012). The career resources model: An integrative framework for career counsellors. British Journal of Guidance \& Counselling, 40(4), 369-383.

Jackson, D., \& Wilton, N. (2016). Developing career management competencies among undergraduates and the role of workintegrated learning. Teaching in Higher Education, 21(3), 266-286.

Lucas, E. B. (1986). College career planning and placement centers: Finding their identity. Journal of Career Development, 13(1), 9-17.

Mason, G., Williams, G., \& Cranmer, S. (2009). Employability skills initiatives in higher education: What effects do they have on graduate labour market outcomes. Education Economics, 17(1), 1-30.

McQuaid, R. W., Green, A., \& Danson, M. (2005). Introducing employability. Urban Studies, 42(2), 191-195.

Osborne, W. L., \& Usher, C. H. (1994). A super approach: Training career educators, career counselors and researchers. Journal of Career Development, 20(3), 219-225.

Sun, V. J., \& Yen, M. (2012). Career guidance and counseling for university students in China. International Journal for the Advancement of Counselling, 34(3), 202-210.

Wehrly, B. (1982). Cultural and social influences on career guidance: An overview. International Journal for the Advancement of Counseling, 5(2), 131-140.

Wu, Y., Tsai, Y., \& Chen, C. (2014). Examining the experiences of career guidance, vocational self-concept, and self-perceived employability among science education majors in Taiwan. Journal of Baltic Science Education, 13(2), $182-190$.

Yorke, M., \& Knight, P. (2007). Evidence-informed pedagogy and the enhancement of student employability. Teaching in Higher Education, 12(2), 157-170. 
NOTES 